\title{
PENGARUH MASASE PAYUDARA TERHADAP BENDUNGAN ASI PADA IBU POST PARTUM DI RSIA KHADIJAH I MAKASSAR
}

\author{
Yusrah Taqiyah ${ }^{1)}$, Sunarti $^{2)}$, Nur Fadilah Rais ${ }^{3)}$ \\ 1,2,3 Program Studi Ilmu Keperawatan, Universitas Muslim Indonesia \\ E-mail : yusrah.taqiyah@yahoo.co.id
}

\begin{abstract}
Abstrak
Masa nifas merupakan masa transisi dari intranatal ke post natal, pada masa ini masalah yang sering terjadi salah satunya adalah bendungan ASI yang disebabkan oleh penyempitan duktus lakteferi oleh kelenjar-kelenjar yang tidak dikosongkan dengan sempurna sehinggah aliran vena dan limfotik tersumbat hal ini menyebabkan payudara bengkak dan sangat nyeri, untuk mengatasi hal tersebut dapat dilakukan dengan cara masase payudara (pijat payudara). Tujuan dari penelitian ini adalah untuk mengetahui pengaruh Masase Laktasi terhadap bendungan ASI pada ibu post partum di RSIA Khadijah 1 Makassar. Penelitian ini adalah jenis penelitian kuantitatif dengan desain quasi eksperimen., dengan pendekatan rancangan pre-test dan post- test with control group. Populasi dalam penelitian ini adalah ibu post partum di RSIA Sitti Khadijah I Makassar pada bulan Juni 2018 dengan menggunakan tehnik accidental sampling. Jumlah sampel sebanyak 16 ibu post partum diberikan intervensi Masase Payudara selama 3 hari dengan durasi 15 menit. Analisa data yang digunakan adalah analisa bivariat dengan uji Paired Sample T test. Berdasarkan dari hasil penelitian Sebelum dilakukan Masase Payudara dari 16 ibu post partum terdapat 81,3\% atau 13 orang ibu post partum yang dikategorikan mengalami bendungan ASI dan setelah dilakukan Masase Laktasi terjadi penurunan bendungan ASI dari 81,3\% menjadi 18,8\%. Kesimpulan Ada pengaruh Masase Laktasi terhadap bendungan ASI dengan nilai p.Value 0.007 Diharapkan agar tetap melakukan masase payudara baik itu sebelum dan setelah melahirkan untuk menghindari terjadinya bendungan ASI dan memperlancar pengeluaran ASI sedini mungkin.
\end{abstract}

Kata Kunci : Post Partum, Bendungan ASI, Masase Payudara

\begin{abstract}
Postpartum period is a transition period from intranatal to post natal, at this time the problem that often occurs one of them is the ASI dam caused by narrowing of the lacteferral duct by glands that are not completely emptied so that venous and lymphotic flow is blocked this causes the breasts to swell and very painful, to overcome this can be done by massage breast (breast massage). The purpose of this study was to determine the effect of Lactation Massage on ASI dams on post partum mothers at RSIA Khadijah 1 Makassar. This research is a kind of quantitative research with a quasi-experimental design, with a pretest and post-test design approach with a control group. The population in this study was post partum mothers in RSUD Sitti Khadijah I Makassar in June 2018 using accidental sampling techniques. The number of samples as many as 16 post partum mothers were given breast massage intervention for 3 days with a duration of 15 minutes. Data analysis used was bivariate analysis with Paired Sample T test. Based on the results of the study, before breast cancer was carried out from 16 post partum mothers there were $81.3 \%$ or 13 post partum mothers who were categorized as having ASI dams and after Masase Lactation the ASI dam decreased from $81.3 \%$ to $18.8 \%$. Conclusion There is the effect of the Lactation Massage on the ASI dam with a value of $\rho$.Value 0.007 It is hoped that it will continue to massage breast both before and after giving birth to avoid the occurrence of ASI dams and facilitate the release of ASI as early as possible.
\end{abstract}

Keywords: Post Partum, ASI Dam, Breast Massage 


\section{PENDAHULUAN}

Di Indonesia sekarang ini mengalami banyak masalah diantaranya masalah gizi yang terjadi pada bayi dan anak. sehingga terjadi kerawanan gizi pada bayi yang lebih banyak disebabkan karena faktor makanan yang kurang, juga karena Air Susu Ibu (ASI) banyak yang diganti dengan susu botol, dengan cara jumlah yang tidak memenuhi kebutuhan (Sholichah, 2011). Masase Payudara merupakan suatu cara merawat payudara yang dilakukan pada saat kehamilan atau masa nifas untuk mendukung produksi air susu ibu (ASI), selain itu untuk kebersihan payudara dan perawatan pada bentuk puting susu yang masuk ke dalam atau datar.

Masalah puting susu bukanlah halangan bagi ibu untuk menyusui dengan baik dengan mengetahui sejak awal, ibu mempunyai waktu untuk mengusahakan agar puting susu lebih mudah sewaktu menyusui. Disamping itu juga sangat penting memperhatikan kebersihan personal hygiene (Rustam, 2013). Adapun masalah yang sering terjadi pada ibu post partum setelah melahirkan ialah terjadinya bendungan ASI (Engorgement) dimana terjadi penyempitan duktus lakteferi atau oleh kelenjar-kelenjar tidak dikosongkan dengan sempurna atau karena kelainan pada puting susu (Manuaba, 2010). Salah satu masalah masyarakat mengenai kejadian bendungan ASI yang disebabkan oleh pengeluaran air susu yang tidak lancar, karena bayi tidak cukup sering menyusu pada ibunya. gangguan ini dapat menjadi lebih parah apabila ibu jarang menyusukan bayinya, akibatnya bayi tidak mendapatkan ASI secara Eksklusif dan apabila tidak segera di tangani maka akan menyebabkan engorgement, hal ini terjadi karena penyempitan duktus lakteferi atau oleh kelenjar-kelenjar tidak dikosongkan dengan sempurna atau karena kelainan pada putting susu sehingga terjadinya pembengkakan pada payudara karena peningkatan aliran vena dan limfe mengakibatkan timbulnya rasa nyeri disertai kenaikan suhu badan. Di Amerika Serikat persentase perempuan menyusui yang mengalami Bendungan ASI rata-rata mencapai $87,05 \%$ atau sebanyak 8242 ibu nifas dari 12.765 orang, pada tahun 2014 ibu yang mengalami bendungan ASI sebanyak 7198 orang dari 10.764 orang dan pada tahun 2015 terdapat ibu yang mengalami bendungan ASI sebanyak 6543 orang dari 9.862 orang (WHO, 2015).

Menurut data ASEAN tahun 2014 disimpulkan bahwa presentase cakupan kasus bendungan ASI pada ibu nifas tercatat 107.654 ibu nifas, pada tahun 2014 terdapat ibu nifas yang mengalami bendungan ASI sebanyak 95.698 orang, serta pada tahun 2015 ibu yang mengalami bendungan ASI sebanyak 76.543 orang. Hal ini disebabkan karena ketidaksadaran masyarakat dalam mendorong peningkatan pemberian ASI. Di Indonesia diperkirakan berjumlah 876.665 orang dan di Sumatera Utara berkisar 40-60\% wanita yang tidak mengerti sama sekali mengenai perawatan payudara (Depkes,2008). Berdasarkan data yang didapatkan dari RSIA Khadijah Makassar pada tiga bulan terakhir yakni bulan April - Juni 2018 diperoleh jumlah ibu melahirkan sebanyak 288 orang. Hasil wawancara yang dilakukan oleh $10 \mathrm{ibu}$ di ruang nifas masih ada yang mengeluh belum menyusui anaknya di hari kedua dikarenakan terjadinya bendungan ASI. Berdasarkan latar belakang di atas maka peneliti tertarik melakukan penelitian dengan tujuan untuk mengetahui pengaruh Masase Payudara terhadap bendungan ASI pada ibu post partum di RSIA Khadijah 1 Makassar.

\section{METODE PENELITIAN}

Jenis penelitian ini adalah penelitian kuantitatif dengan desain Quasi eksperimen dengan rancangan pre dan post test without control, penelitian ini dilakukan dengan cara menilai bendungan ASI melalui lembar observasi sebelum dan setelah dilakukan Masase Payudara, intervensi dilakukan sebanyak 2 kali perhari pagi dan sore selama 3 hari berturut-turut dengan durasi intervensi 15 menit sesuai SOP pada setiap responden. Jarak antara pre dan post intervensi selama 3 hari, penelitian ini dilaksanakan di ruang nifas RSIA Khadijah I Makassar, mulai bulan Juni-November 2018. Tehnik pengambilan sampel dalam penelitian ini menggunakan accidental sampling dengan jumlah 16 responden yang ditentukan sesuai dengan kriteria inklusi. Pengambilan data menggunakan lembar observasi pelaksanaan perawatan payudara dan lembar kuesioner untuk kejadian bendungan ASI. Analisa data dengan 
menggunakan Uji statistic MC nemar dan menggunakan komputerisasi dengan tingkat kemaknaan $\alpha=0,05$.

\section{HASIL PENELITIAN}

Tabel. 1 : Distribusi karakteristik Responden berdasarkan Umur, Pendidikan, Pekerjaan, dan Paritas Di RSIA Khadijah 1 Makassar

\begin{tabular}{|c|c|c|}
\hline \multirow{2}{*}{ Karakteristik } & \multicolumn{2}{|c|}{ Jumlah } \\
\cline { 2 - 3 } & n & \% \\
\hline Umur & 12 & 75 \\
25-30 tahun & 4 & 25 \\
36-40 tahun & & \\
\hline Tingkat Pendidikan & 2 & 12.5 \\
SMP & 9 & 56.25 \\
SMA & 5 & 31.25 \\
Perguruan Tinggi & & \\
Pekerjaan & 11 & 68,75 \\
IRT & 5 & 31,25 \\
Pegawai Swasta & & \\
\hline Paritas & 12 & 75 \\
Primigravida & 4 & 25 \\
Multigravida &
\end{tabular}

Dari Tabel 1 menunjukkan karakteristik responden ibu post partum berdasarkan umur terbanyak yaitu pada masa dewasa awal yang berumur 25-30 tahun sebanyak 75\% dan yang terendah yaitu pada masa dewasa akhir yang berumur 36-40 tahun sebanyak $25 \%$. Dan karakteristik berdasarkan pendidikan yang terbanyak pada tingkatan SMA sebanyak 56,25 $\%$ dan terendah pada tingkatan SMP sebanyak $12,5 \%$, dan kerakteristik berdasarkan pekerjaan, terbanyak pada profesi IRT sebanyak 68,75\% dan terendah pada profesi pegawai swasta sebanyak 31,25 \% sedangkan karakteritik berdasarkan paritas yang terbanyak terdapat pada primigravida sebanyak $75 \%$ dan terendah pada multigravida sebanyak $25 \%$
Tabel. 2 : Distribusi karakteristik Responden Bendungan ASI Sebelum Masase Payudara Di RSIA Khadijah 1 Makassar

\begin{tabular}{|c|c|c|}
\hline \multirow{2}{*}{ Bendungan ASI } & \multicolumn{2}{|c|}{ Jumlah } \\
\cline { 2 - 3 } & $\mathrm{n}$ & $\%$ \\
\hline Terbendung & 16 & 100 \\
\hline Total & $\mathbf{1 6}$ & $\mathbf{1 0 0}$ \\
\hline
\end{tabular}

Sumber : data primer, 2018

Tabel.2 menunjukkan bahwa yang mengalami bendungan ASI sebelum dilakukan perawatan payudara didapatkan hasil Tidak Terbendung sebanyak $18,8 \%$ dan Terbendung sebanyak $81,3 \%$

Tabel. 3 : Distribusi karakteristik Responden Bendungan ASI Setelah Masase Payudara Di RSIA Khadijah 1 Makassar

\begin{tabular}{|c|c|c|}
\hline \multirow{2}{*}{ Bendungan ASI } & \multicolumn{2}{|c|}{ Jumlah } \\
\cline { 2 - 3 } & $\mathrm{n}$ & $\%$ \\
\hline Tidak terbendung & 13 & 81.3 \\
\hline Terbendung & 3 & 18.8 \\
\hline Total & $\mathbf{1 6}$ & $\mathbf{1 0 0}$ \\
\hline
\end{tabular}

Sumber : data primer, 2018

Tabel.3 menunjukkan bahwa yang mengalami bendungan ASI setelah dilakukan perawatan payudara didapatkan hasil Tidak Terbendung sebanyak $81,3 \%$ dan Terbendung sebanyak $18,8 \%$.

Tabel. 4 : Pengaruh Masase Payudara Terhadap Bendungan ASI Pada Ibu Post Partum di RSIA Khadijah 1 Makassar

\begin{tabular}{|c|c|c|c|c|c|}
\hline \multirow{2}{*}{$\begin{array}{c}\text { Bendungan } \\
\text { ASI }\end{array}$} & \multicolumn{2}{|c|}{ Pre } & \multicolumn{2}{|c|}{ Post } & \multirow{2}{*}{$\rho$} \\
\cline { 2 - 5 } & $\mathrm{n}$ & $\%$ & $\mathrm{n}$ & $\%$ & \\
\hline Terbendung & 3 & 81.3 & 3 & 18,8 & \multirow{2}{*}{0,007} \\
\hline $\begin{array}{c}\text { Tidak } \\
\text { terbendung }\end{array}$ & 13 & 18,8 & 13 & 81,3 & \\
\hline
\end{tabular}

Sumber : Data primer 2018 
Tabel.4 menunjukkan bahwa ibu post partum yang mengalami bendungan ASI sebelum dilakukan perawatan payudara sebanyak $81,3 \%$ dan tidak terbendung sebanyak $18,8 \%$. Namun setelah dilakukan perawatan payudara, data yang didapatkan mengalami penurunan, dimana yang mengalami bendungan ASI sebanyak 18,8\% dan yang tidak mengalami bendungan ASI sebanyak 81,3\%. Berdasarkan hari Uji paired t-test didapatkan hasil $(\alpha=0,05)$ yang berarti bahwa terdapat pengaruh hubungan Masase ASI pada ibu Post Partum di RSIA Khadijah I Muhammadiyah Khadijah Makassar

\section{PEMBAHASAN}

Penelitian ini menunjukkan terdapat perbedaan yang bermakna pada bendungan ASI sebelum dan setelah dilakukan Masase Laktasi. Masase Laktasi dengan baik, dapat menghasilkan produksi ASI yang lebih banyak, hal ini didukung oleh teori dan pendapat para ahli antara lain menurut (saryono, 2011) bahwa perawatan payudara saat kehamilan memiliki beberapa manfaat, antara lain : menjaga kebersihan payudara terutama kebersihan putting susu, melenturkan dan menguatkan putting susu sehingga memudahkan bayi menyusui, merangsang kalenjar-kalenjar air susu sehingga produksi ASI banyak dan lancar dapat mendeteksi kelainan-kelainan payudara secara dini dan melakukakn upaya untuk mengatasinya mempersiapkan mental (psikis) ibu untuk menyusui. Berdasarkan analisa peneliti menunjukkan bahwa masih ada beberapa ibu post partum yang mengalami bendungan ASI ini disebabkan karena 12 responden primigravida atau anak pertama sehinggah pengalaman responden masih kurang dalam mengatasi bendungan ASI. Selain itu ada faktor lain yang masih menyebabkan terjadinya bendungan ASI ialah karena ada beberapa ibu post partum yang mengalami benjolan pada payudara serta terdapat lecet pada putting susu sehingga peneliti tidak dapat memberikan perawatan payudara secara maksimal karena ibu merasakan sakit pada daerah payudara. Oleh karena itu perawatan payudara perlu dilakukan sebelum dan sesudah melahirkan. Bendungan ASI (Engorgement) merupakan pembendungan ASI karena penyempitan duktus laktiferus atau kelenjar-kelenjar ASI yang tidak dikosongkan dengan sempurna atau karena kelainan putting susu, payudara yang membengkak ini biasanya terjadi sesudah melahirkan pada hari ketiga atau ke empat. Secara patofiologis sejak hari ketiga sampai hari keenam pasca persalinan ketika ASI secara normal dihasilkan, payudara menjadi sangat penuh, hal ini bersifat fisiologis dengan pengihisapan yang efektif dan pengeluaran ASI oleh bayi. Namun keadaan ini bisa terjadi bendungan karena payudara akan terisi sangat penuh dengan ASI dan cairan jaringan. Aliran limfotik akan tersumbat, aliran susu menjadi terhambat dan saluran ASI dan alveoli akan meningkat. Payudara akan terbendung, membesar, membengkak, dan sangat nyeri. Payudara dapat terlihat mengkilat dan edema di daerah eritema difus, putting susu akan teregang menjadi rata, ASI tidak mengalir dengan mudah dan bayi akan sulit mengenyut untuk menghisap ASI (Amelia, 2010). Masalah yang sering timbul selama masa menyusui yang dimulai sejak periode antenatal, masa pasca persalinan dini (nifas atau laktasi) dan masa persalinan lanjut. Salah satu masalah menyusui pada masa pasca persalinan dini adalah putting susu terasa nyeri, putting susu lecet, payudara bengkak, dan biasanya terjadi mastitis (Ambarwati \& Wulandari, 2011). Setelah dilakukan Perawatan Payudara pada Ibu Post Partum. yang mengalami bendungan ASI terdapat 18,3\% dan yang tidak mengalami bendungan ASI sebanyak $81,3 \%$. Hal ini merupakan manfaat dari gerakan menyusui, biasanya harus dikosongkan dengan jalan memompa atau mengurut. pada perawatan payudara yang bermanfaat melancarkan reflex pengeluaran ASI. Selain itu juga merupakan cara efektif meningkatkan volume ASI dan paling penting mencegah terjadinya bendungan ASI. Selain perawatan payudara terdapat pula faktorfaktor yang memengaruhi kelancaran pengeluaran ASI seperti makanan, gizi ibu saat menyusui, kondisi psikis, faktor istirahat, dan faktor isapan anak (Pramita, 2012). Menurut penelitian yang dilakukan oleh Indiarti (2010) cara meningkatkan kualitas ASI bukan hanya melakukan Perawatan Payudara namun juga diperlukan minum 8-12 gelas perhari. Daun pucuk katuk dan sayur asin membuat ASI lebih banyak keluar. Faktor jiwa pun penting, ibu 
yang lebih tenang lebih banyak mengeluarkan ASI daripada ibu yang mengalami kesedihan. Cara terbaik untuk menjamin pengeluaran ASI ialah mengusahakan agar setiap kali menyusui dada betul-betul kosong, karena pengosongan buah dada untuk membuat susu lebih banyak, sebab buah dada akan terisap abis antara lain disebakan bayi lemah, putting susu lecet. Hasil penelitian ini sejalan dengan peneliatian yang dilakukan oleh Amelia, 2006 menunjukkan bahwa perawatan payudara membawa dampak positif dalam meningkatkan produksi ASI. Salah satu masalah yang terjadi karena kurangnya perawatan payudara adalah penurunan hormone yaitu prolactin dan oksitosin, prolactin mempengaruhi jumlah produksi ASI, sedangkan oksitosin mempengaruhi proses pengeluaran ASI, perawatan payudara sangat penting salah satunya menjaga kebersihan payudara, terutama kebersihan putting susu agar terhindar dari infeksi, melunakkan serta memperbaiki bentuk putting susu sehinggah bayi dapat menyusu dengan baik, merangsang kelenjar-kelenjar dan hormone prolactin dan oksitosin untuk meningkatkan produksi ASI lancer serta mengetahui secara dini kelainan putting susu dan melakukan usaha-usaha untuk mengatasinya (Amalia, 2006)

\section{KESIMPULAN}

Sebelum dilakukan perawatan payudara dari 16 ibu post partum terdapat 81,3\% atau 13 orang ibu post partum yang dikategorikan mengalami bendungan ASI. Setelah dilakukan perawatan payudara terjadi penurunan bendungan ASI dari 81,3\% menjadi 18,8\%. Ada pengaruh Masase Payudara terhadap bendungan ASI dengan nilai $\rho$.Value 0.007

Diharapkan agar tetap melakukan perawatan payudara baik sebelum dan setelah melahirkan untuk menghindari terjadinya bendungan ASI dan mmeperlancar pengeluaran ASI

\section{REFERENSI}

1. Anik maryunani, (2012). Inisiasi Menyesui Dini, Asi Eksklusif dan Manajemen Laktasi. Jakarta : TIM

2. Anggraini. (2010). Asuhan Kebidanan Masa Nifas. Yogyakarta: Pustaka Rihama
3. Amalia, 2006. Pengaruh Perawatan Payudara Terhadap Peningkatan Volume ASI. http://els.fk.umiy.a.id . Diakses tanggal 28 Oktober 2018

4. Atikah Proverawati. (2010). Kapita Seleksi ASI dan Menyusui. Jogjakarta. Muha Medika

5. Atikah \& Eni Rahmawati, (2013). Kopita selekta asi \& menyusui. Yogyakarta Nuha Medika

6. Depkes, 2018. Perawatan Payudara Pada Ibu Hamil. http//www.Depkes.go.id. diakses tanggal 25 Agustus 2018

7. Marmi. (2012). Panduan Lengkap Manajemen Laktasi. Yogyakarta: Nuha

8. Medika. Megawati. (2013). Pengaruh Perawatan Payudara Terhadap Produksi ASI Pada Ibu Post Partum. Jurnal Kesehatan.

9. Retnayu Pradanie. (2015) Paket dukungan terhadap breastfeeding self efficacy dan keberhasilan menyusui pada ibu post partum. Vol. 10. Universitas Airlangga: Jurnal

10. Saryono. (2010). Perawatan Payudara. Yogyakarta: Mitra Cendekia

11. Saryono dan Primatasari. (201)2. Perawatan Payudara Dilengkapi dengan Deteksi Dini Terhadap Penyakit Payudara. Jogjakarta. Mitra Cendekia. Press.

12. Soetjiningsih. (2012). ASI Petunjuk Untuk Tenaga Kesehatan. Jakarta. EGC

13. Wiji dan Rizki, (2013). Asi dan Panduan Menyusui. Yogyakarta :Nuha Medika 